\title{
Oral epithelial cells inhibit the proliferation, mRNA expressions of collagen type I, RUNX2 and BGP, and ALP activity of osteoblast-like cells in co- culture.
}

\author{
Kenichi Matsuzaka $^{1 * \#}$, Tadashi Horikawa ${ }^{1 \#}$, Eitoyo Kokubu², Takashi Inoue ${ }^{1}$ \\ ${ }^{1}$ Department of Clinical Pathophysiology, Tokyo Dental College, 2-9-18, Canda-Misakicho, Chiyoda-ku, Tokyo, Japan \\ ${ }^{2}$ Department of Microbiology, Tokyo Dental College, 2-9-18, Canda-Misakicho, Chiyoda-ku, Tokyo, Japan
}

${ }^{\#}$ These authors contributed equally to this work

\begin{abstract}
Cell-to-cell interactions play important roles in regulating cell proliferation and differentiation, tissue production, organ construction and ontogenesis. The purpose of this study was to investigate the effects of oral epithelial (OE) cells on osteoblasts' behavior for proliferation and osteogenic differentiation. Osteoblast-like cells were co-cultured in 6-well-dishes with or without $\mathrm{OE}$ cells growing on cell culture inserts. After 1, 3, 7 and $14 \mathrm{~d}$, the characteristics of osteoblast-like cells were evaluated regarding cell proliferation, mRNA expression levels of collagen type I, RUNX2 and bone Gla protein (BGP), and alkaline phosphate (ALP) activity. In cell proliferation assays, the numbers of osteoblast-like cells cultured with or without $\mathrm{OE}$ cells increased over time for $2 \mathrm{w}$, but the proliferation of osteoblast-like cells co-cultured with $O E$ cells plateaued after $7 \mathrm{~d}$. The mRNA expression levels of type I collagen in osteoblast-like cells cultured with or without $\mathrm{OE}$ cells tended to decrease over time, but the decrease in osteoblast-like cells co-cultured with $\mathrm{OE}$ cells was more dramatic. The mRNA expression levels of RUNX2 and BGP in osteoblast-like cells cultured without OE cells tended to increase over time, but those increases in cells cultured without $\mathrm{OE}$ cells were more dramatic than in osteoblast-like cells cocultured with OE cells. The ALP activity of osteoblast-like cells cultured without $O E$ cells increased until $7 \mathrm{~d}$ and then decreased at $14 \mathrm{~d}$, but osteoblast-like cells cultured with $\mathrm{OE}$ cells underwent little change in ALP activity throughout the $14 \mathrm{~d}$ of culture. The ALP activity of osteoblast-like cells cultured without OE cells was significantly higher at 7 and $14 \mathrm{~d}$ than in osteoblast-like cells cultured with $\mathrm{OE}$ cells. In conclusion, these results indicate that $\mathrm{OE}$ cells inhibit the osteogenic differentiation and function of osteoblast-like cells.
\end{abstract}

Keywords: Co-culture, Osteoblast-like cell, Oral epithelial cell, RUNX2, Bone Gla protein, ALP activity. Accepted on July 30, 2018

\section{Introduction}

Cell-to-cell interactions play important roles in regulating cell proliferation and differentiation, tissue production, organ construction, ontogenesis, and so on. Periodontal tissue is a unique tissue that is covered by oral epithelial (OE) tissue and contacts the tooth root connecting the alveolar bone with fibrous connective tissues [1]. Periodontal tissue is maintained by various kinds of cell interactions. The mutual relationship between epithelial and mesenchymal tissues plays an important role in tissue development and in the homeostatic mechanism. Our group has reported the cell behavior of several kinds of periodontal cells using a co-culture system [2-9]. Matsuzaka et al. developed the co-culture technique and demonstrated that the presence of epithelial rest of Malassez' (ERM) cells reduces the functions of hard tissue formation of periodontal ligament (PDL) fibroblasts [2] and prevents PDL fibroblasts from being susceptible to dento-alveolar ankyloses when a compression force is applied [3]. Furthermore, ERM cells may induce PDL fibroblasts to resorb the alveolar bone for protection against lipopolysaccharides derived from Porphyromonas gingivalis [4,5]. Yasumura et al. and Morikawa et al. suggested from an in vitro experiment with dental pulp cells and PDL cells that dental pulp cells influence PDL cells regarding osteoclastogenesis and odontoclastogenesis against mechanical stress [6,7]. Bai et al. reported about bone formation from dental follicle cells cocultured with dental papilla cells [8] and about cementum and PDL tissue formation co-cultured with Herwig's epithelial root sheath cells [9].

It is known that there are two types of healing reactions of periodontitis: long epithelial junctions and connective tissue healing involving the formation of reparative cementum [10]. 
Noguchi et al. concluded that the destruction of periodontal tissue is increased in tissues containing a long junctional epithelium compared with a normal junctional epithelium [11]. This means that the OE approaches the alveolar bone destroying the PDL and the alveolar bone. There are few studies that have compared the effects of $\mathrm{OE}$ cells on osteoblasts. So, the purpose of this study was to investigate the effects of OE cells on osteoblasts' behavior for proliferation and osteogenic differentiation.

\section{Materials and Methods}

\section{Cultured cells}

OE cells were obtained from mouse gingiva, using the modified method described by Kondo et al. [12]. Briefly, the gingival mucosa was digested with dispase $(4 \mathrm{mg} / \mathrm{ml}$, Wako, Tokyo, Japan) at $37^{\circ} \mathrm{C}$ for $30 \mathrm{~min}$, after which the $\mathrm{OE}$ tissue was "peeled off" using forceps. The epithelium was then minced into smaller pieces using forceps and was dissociated using $1.25 \%$ trypsin- $0.5 \%$ ethylenediaminetetraacetic acid (EDTA) in Dulbecco's phosphate buffered saline (Sigma, St. Louis, MO, USA) at $37^{\circ} \mathrm{C}$ for $15 \mathrm{~min}$ to obtain a suspension of OE cells. Enzymatic treatment was stopped by adding a trypsin inhibitor (DS Pharma Biomedical, Osaka, Japan) and the OE cells were then cultured. MC3T3-E1 cells (Riken, Saitama, Japan) were used as osteoblast-like cells.

\section{Co-culture of cells}

The co-culture system was carried out as previously described by Matsuzaka et al. [2-5]. Briefly, osteoblast-like cells were seeded at a density of $5.0 \times 10^{3}$ cells per $\mathrm{cm}^{2}$ in 6-well-dishes (BD Falcon, Franklin Lakes, NJ, USA). OE cells were seeded at a density of $5.0 \times 10^{3}$ cells per $\mathrm{cm}^{2}$ on cell culture inserts which have $0.4 \mu \mathrm{m}$ pores (BD Falcon). These cells were then cultured in $\alpha$-MEM containing $10 \%$ fetal bovine serum (incubated at $56^{\circ} \mathrm{C}$ for $35 \mathrm{~min}$, Gibco, Tokyo, Japan) and antibiotic (gentamycin, SIGMA). Osteoblast-like cells were detached at $\mathrm{d} 1,3$ and 7 using a trypsin/EDTA solution after removing the cell insert dishes.

\section{Evaluations of osteoblast-like cells}

After 1, 3, 7 and $14 \mathrm{~d}$, osteoblast-like cells growing in the 6well culture plates were collected using $0.1 \%$ trypsin, and the numbers of cells were counted using a Coulter Counter.

To measure mRNA expression levels of collagen type I, RUNX2 and BGP, osteoblast-like cells were homogenized in 1 $\mathrm{ml} \mathrm{TRIsol}{ }^{\circledR}$ reagent (Invitrogen, Tokyo, Japan) and each solution was transferred to a $1.5 \mathrm{ml}$ tube containing chloroform and was then mixed. Each tube was centrifuged at 13,200 rpm at $4^{\circ} \mathrm{C}$ for $20 \mathrm{~min}$, after which each supernatant was placed in a $1.5 \mathrm{ml}$ tube containing $250 \mu \mathrm{l} 100 \%$ isopropanol $\left(1 / 4^{\text {th }}\right.$ the amount of TRIsol) at $-80^{\circ} \mathrm{C}$ for $1 \mathrm{~h}$. After centrifugation at $13,200 \mathrm{rpm}$ for $20 \mathrm{~min}$ at $4^{\circ} \mathrm{C}$, the supernatants were discarded and the remaining total RNA pellets were washed with $70 \%$ cold ethanol and dissolved in $50 \mu \mathrm{l}$ RNAase-free (DEPC- treated) water. Total RNAs were reverse transcribed and amplified in $20 \mu \mathrm{l}$ volumes using a Quanti-Tect Reverse Transcription $\mathrm{Kit}^{\circledR}$ (Qiagen Inc., Hilden, Germany) containing RNA PCR Buffer, 2 U/1 RNAase inhibitor, $0.25 \mathrm{U} / \mathrm{M}$ reverse transcriptase, $0.125 \mathrm{M}$ oligo dt-adaptor primer, $5 \mathrm{mM} \mathrm{MgCl}_{2}$ and RNAase-free water. RT-PCR products were analysed by quantitative real-time RT-PCR in TaqMan Gene Expression Assays $^{\circledR}$ (Applied Biosystems, Foster City, CA, USA) for the following target genes: type I Collagen (Rn01463848_m1, Applied Biosystems), RUNX2 (Rn01512296_m1, Applied Biosystems) and BGP (Rn00566386_g1, Applied Biosystems). The TaqMan Endogenous Control (Applied Biosystems) for the target gene $\beta$-actin was used as a control. All PCRs were performed using a real time PCR 7500 Fast System ${ }^{\circledR}$. Gene expression quantitation using TaqMan Gene Expression Assays ${ }^{\circledR}$ was performed as the second step in a two-step RTPCR. Assays were done in $20 \mu \mathrm{l}$ single-plex reactions containing TaqMan Fast Universal PCR Master Mix ${ }^{\circledR}$, TaqMan Gene Expression Assays $^{\circledR}$, distilled water and cDNA, according to instructions provided by the manufacturer (Applied Biosystems). Reaction conditions consisted of a primary denaturation at $95^{\circ} \mathrm{C}$ for $20 \mathrm{~s}$, then cycling for 40 cycles at $95^{\circ} \mathrm{C}$ for $3 \mathrm{~s}$ and at $62^{\circ} \mathrm{C}$ for $30 \mathrm{~s}$. PCR data are reported compared to the corresponding control. Quantitative RT-PCR analyses were reproduced 4 times.

For measurement of ALP activity, protein concentrations in the supernatants were determined using a protein assay kit (Coomassie Plus Protein Assay Reagent Kit ${ }^{\circledR}$, Takara Bio Inc., Otsu, Japan) as follows: A $150 \mu$ l aliquot of each supernatant as described above was added to $150 \mu \mathrm{l}$ of the Coomassie reagent in a 96-well culture plate. After mixing the plate for 30 $\mathrm{s}$, absorbance was measured at $595 \mathrm{~nm}$ using a microplate reader $\left(\mathrm{iMark}^{\circledR}\right.$, Bio-Rad Laboratories, Inc., Hercules, CA, USA). These operations were carried out on ice. Enzymatic activities were finally determined by absorbance values of reaction products per min, and the results are evaluated as specific activity, calculated according to the following formula: ALP specific activity $(\mathrm{IU} / \mathrm{mg})=\mathrm{ALP}$ concentration $(\mathrm{IU} / \mathrm{ml}) /$ protein concentration $(\mathrm{mg} / \mathrm{ml})$.

\section{Results}

The cell proliferation assay showed that the numbers of osteoblast-like cells cultured with or without OE cells increased over time in the $14 \mathrm{~d}$ experimental period but the proliferation of osteoblast-like cells cultured with OE cells plateaued after $7 \mathrm{~d}$ (Figure 1). There was a significant difference in the number of osteoblast-like cells cultured with or without $\mathrm{OE}$ cells at $14 \mathrm{~d}(\mathrm{P}<0.05)$.

The mRNA expression levels of type I collagen in osteoblastlike cells cultured with or without OE cells tended to decrease each day, but the decrease in osteoblast-like cells cultured with $\mathrm{OE}$ cells was more dramatic than in those cultured without $\mathrm{OE}$ cells $(\mathrm{P}<0.05)$ at $7 \mathrm{~d}$ (Figure 2). Although the mRNA expression levels of RUNX2 of osteoblast-like cells cultured without OE cells tended to increase each day, there was little change in the mRNA expression level of RUNX2 in 


\section{of osteoblast-like cells in co-culture}

osteoblast-like cells cultured with OE cells (Figure 3), but there was a significant difference at $7 \mathrm{~d}(\mathrm{P}<0.05)$.

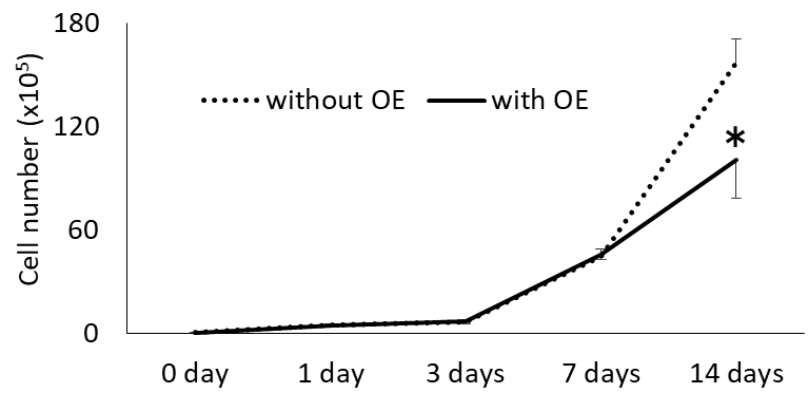

Figure 1. Proliferation of osteoblast-like cells in culture. The numbers of osteoblast-like cells cultured with or without OE cells increased over the 14 d experimental period, but the proliferation of osteoblast-like cells cultured with OE cells plateaued after $7 d$ $\left({ }^{*} P<0.05\right)$.

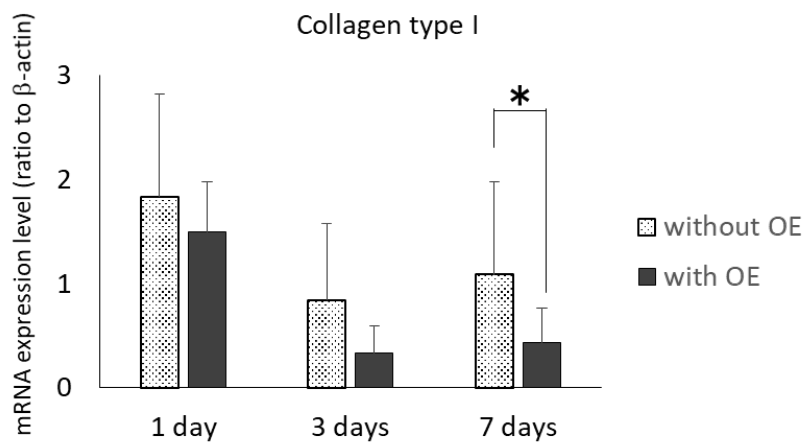

Figure 2. $m R N A$ expression levels of collagen type I in osteoblast-like cells. The mRNA expression levels of type I collagen in osteoblast-like cells cultured with or without OE cells decreased each day, but the decrease in osteoblast-like cells cultured with $O E$ cells was more dramatic than in those cultured without OE cells $\left({ }^{*} P<0.05\right)$.

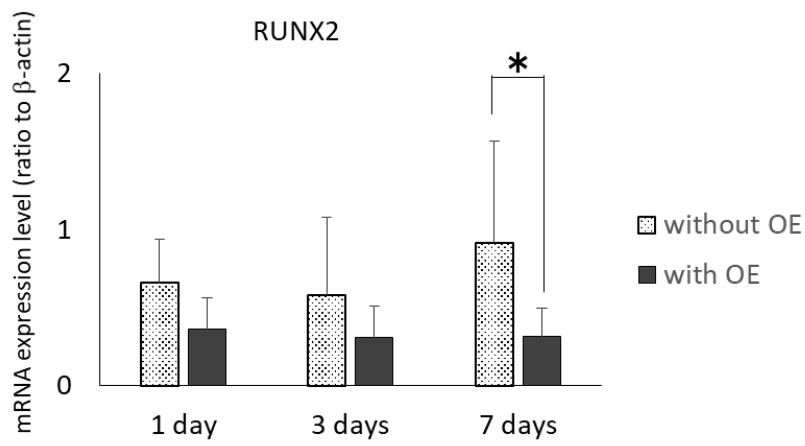

Figure 3. $m R N A$ expression levels of RUNX2 in osteoblast-like cells. The mRNA expression levels of RUNX2 in osteoblast-like cells cultured without OE cells tended to increase each day, but there was little change in the mRNA expression levels of RUNX2 in osteoblastlike cells cultured with OE cells $\left({ }^{*} P<0.05\right)$.

The mRNA expression levels of BGP in osteoblast-like cells cultured with or without $\mathrm{OE}$ cells tended to increase each day (Figure 4), and further, the increase in osteoblast-like cells cultured without $\mathrm{OE}$ cells was more dramatic than in those cultured with $\mathrm{OE}$ cells $(\mathrm{P}<0.05)$ at $7 \mathrm{~d}$.

The ALP activity of osteoblast-like cells cultured without OE cells increased until $7 \mathrm{~d}$ of incubation and then decreased at 14 $\mathrm{d}$, but osteoblast-like cells cultured with OE cells had only small changes throughout the $14 \mathrm{~d}$ experimental period (Figure 5). The ALP activity of osteoblast-like cells cultured without $\mathrm{OE}$ cells was significantly higher at 7 and $14 \mathrm{~d}$ than in osteoblast-like cells cultured with $\mathrm{OE}$ cells $(\mathrm{P}<0.01)$.

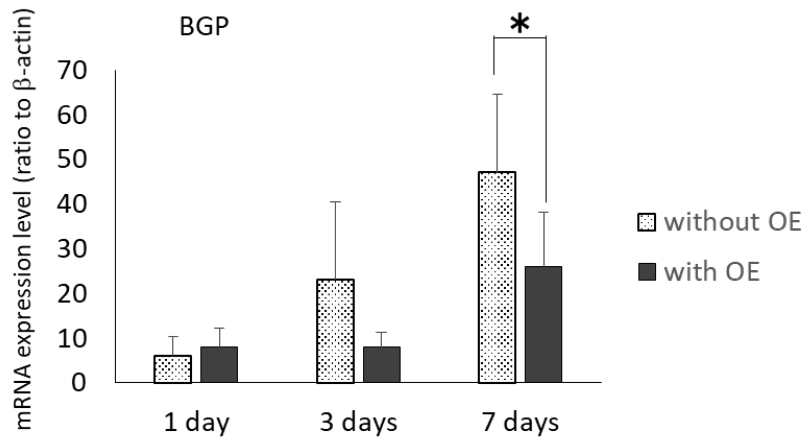

Figure 4. $m R N A$ expression levels of BGP in osteoblast-like cells. The $m R N A$ expression levels of BGP in osteoblast-like cells cultured with or without OE cells increased each day. The increase of BGP $m R N A$ in osteoblast-like cells cultured without $O E$ cells was more dramatic than in osteoblast-like cells cultured with OE cells at $7 d\left({ }^{*} P<0.05\right)$.

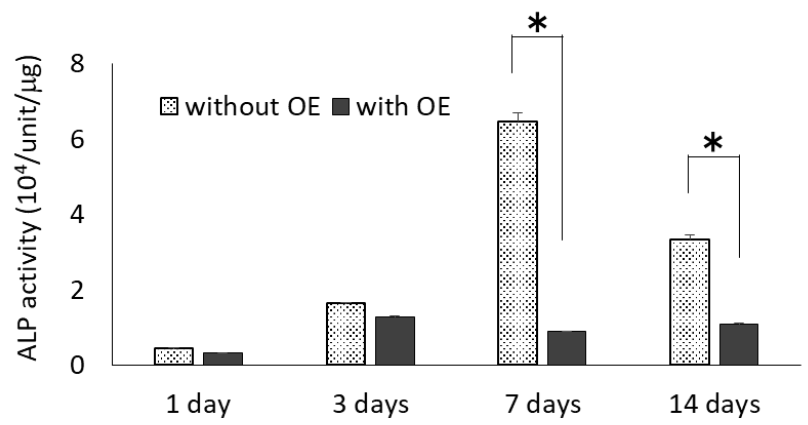

Figure 5. ALP activity of osteoblast-like cells. The ALP activity of osteoblast-like cells cultured without OE cells increased until $7 \mathrm{~d}$ of incubation but then decreased at $14 \mathrm{~d}$. The ALP activity in osteoblastlike cells cultured without $O E$ cells was significantly higher at 7 and $14 d$ than in osteoblast-like cells cultured with OE cells $\left({ }^{*} P<0.01\right)$.

\section{Discussion}

The oral epithelium is a thick mucosal epithelium that protects hard and soft tissues from physical, chemical and bacterial exogenous stimulation. However, the penetration of teeth through the oral epithelium into the oral cavity compromises this barrier, so, the gingiva must form a strong impenetrable bond with the tooth surface in order to maintain the protection of the submucosal tissue. This seal around each tooth extends from the bottom of the oral sulcus epithelium to the top of the alveolar bone and is comprised of both epithelial and connective tissue components. The attachment structure is 
usually less than $2 \mathrm{~mm}$ in width and is termed the "biological width" [13]. There is also a biologic width of 3-4 mm around dental implants, slightly wider than that around natural teeth [14]. Epithelial tissue is generally non-adjacent to the bone, and these two tissues also maintain a certain distance, a phenomenon called the "biological length". The invasion of epithelial tissue into the periodontal pocket, which is the pathogen of periodontal disease, causes the collapse of homeostasis and increases alveolar bone resorption and osteoblast suppression. Although it is known that the junctional epithelium connects to the enamel and the oral epithelium contacts the cementum after the relief of periodontal disease but not to the bone, we assumed that there was a long junctional epithelium following the healing of periodontal disease in this in vitro experimental design. The expression of CK19 in the long junctional epithelium was weaker than in normal junctional epithelium [15]. On the other hand, Shimono et al. and Presland and Dale reported that the normal junctional epithelium is wholly immunoreactive for CK19, but the oral mucosal epithelium is only weakly immunoreactive for CK19 $[16,17]$. Thus, the investigation of relationships between OE cells and osteoblasts is significant for the pathogens of periodontal disease.

For osteogenic transformation, undifferentiated mesenchymal cell starts to express of RUNX2 which is one of the transcription factors to osteoblast, then secretes collagen type I as a matrix for calcification. For the calcification of matrix, BGP plays an important role for the calcification of matrix. The mRNA levels of collagen type I and RUNX2 are known as osteosis-related genes [18]. BGP mRNA is the marker for late stage of osteogenic differentiation and for bone and other kinds of hard tissue formation [2]. The ALP activity is the protein level marker for osteogenesis differentiation [18]. Osteoblastlike cells normally differentiate when they are independently cultured, but there was little change in the expression levels of RUNX2 and BGP mRNAs in osteoblast-like cells co-cultured with OE cells and their ALP expression also increased a little. This phenomenon suggests that epithelial cells that invade close to the bone do not maintain the "biologic width". Suzumura et al. reported that the long junctional epithelium is produced by treatment with bacterial protease, thus it is thought that these two phenomena have an additive effect [19]. Furthermore, it is well known that bacterial infections cause the resorption of alveolar bone. Our group demonstrated that the interleukin-1 $\alpha-6$ mRNA expression levels of PDL fibroblasts are stimulated by sonicated Porphyromonas gingivalis [5]. Although the biological length of the periodontal area is smaller than that of other body areas because of the presence of teeth which are implants into the alveolar bone through the oral epithelium, periodontal diseases cause the oral epithelium to grow down along the tooth root and close to the alveolar bone. The oral epithelium contacting the bone tissue means the collapse of biological morphology as a homeostasis, and bone formation could not maintain homeostasis. Oral implants function by implanting bone tissue through the oral epithelium, so it is easy for epithelial cells to grow close to the bone tissue.
In conclusion, the results of this study indicate that $\mathrm{OE}$ cells inhibit osteogenic differentiation and the function of osteoblast-like cells, and prevent the downgrowth of the oral epithelium around dental implants that leads to maintain osseointegration.

\section{Acknowledgments}

This work was supported by JSPS KAKENHI Grant Number $17 \mathrm{~K} 11630$.

\section{References}

1. Berkovitz BK, Whatling R, Barrett AW, Omar SS. The structure of bovine periodontal ligament with special reference to the epithelial cell rests. J Periodontol 1997; 68: 905-913.

2. Matsuzaka K, Kokubu E, Inoue T. The effects of epithelial rests of Malasssez cells on periodontal ligament fibroblasts: a co-culture investigation for epithelial mesenchymal interactions. Oral Med Pathol 2011; 16: 15-19.

3. Matsuzaka K, Kokubu E, Inoue T. The effects of epithelial rests of Malassez cells on periodontal ligament fibroblasts against centrifugal forces in vitro. J Oral Maxillofac Surg Med Pathol 2013; 25: 174-178.

4. Matsuzaka K, Kokubu E, Inoue T. Effect of epithelial rests of Mallassez cells on RANKL mRNA expression and ALP activity by periodontal ligament fibroblasts stimulated with sonicated Porphiyromonas gingivalis in vitro. J Oral Maxillofac Surg Med Pathol 2014; 26: 554-557.

5. Matsuzaka K, Kokubu E, Inoue T. The effects of epithelial rest of Malassez cells on Interleukin-1??-6 mRNA expression by periodontal ligament fibroblasts stimulated with sonicated Porphyromonas gingivalis in vitro. J Oral Maxilofac Surg Med Pathol 2015; 27: 876-879.

6. Yasumura T, Nishii Y, Matsuzaka K, Inoue T, Sueishi K. Expression of RANKL and OPG mRNAs in rat periodontal ligament cells following mechanical stress and co-culture with rat dental pulp cells in vitro. Clin Dent Res 2014; 28: 3-11.

7. Morikawa T, Matsuzaka K, Nakajima K, Yasumura T, Sueishi K, Inoue T. Dental pulp cells promote the expression of receptor activator of nuclear factor-kB ligand, prostaglandin E2 and substance $\mathrm{P}$ in mechanically stressed periodontal ligament cells. Arch Oral Biol 2016; 70: 158-164.

8. Bai Y, Bai Y, Matsuzaka K, Hashimoto S, Kokubu E, Wang $\mathrm{X}$, Inoue T. Formation of bone-like tissue by dental follicle cells co-cultured with dental papilla cells. Cell Tissue Res 2010; 342: 221-231.

9. Bai Y, Bai Y, Matsuzaka K, Hashimoto S, Fukuyama T, Wu L, Miwa T, Liu X, Wang X, Inoue T. Cementum- and periodontal ligament-like tissue formation by dental follicle cell sheets co-cultured with Hertwigs epithelical rooth sheath cells. Bone 2011; 48: 1417-1426. 
of osteoblast-like cells in co-culture

10. Ehnevid H, Jansson L, Lindskog S, Blomlof L. Quality of periodontal healing. III: Periodontal width following long epithelial junction or reparative cementum formation. Swed Dent J 1994; 18: 173-179.

11. Noguchi S, Ukai T, Kuramoto A, Yoshinaga Y, Nakamura H, Takamori Y, Yamashita Y, Hara Y. The histopathological comparison on the destruction of the periodontal tissue between normal junctional epithelium and long junctional epithelium. J Periodontal Res 2017; 52: 74-82.

12. Kondo M, Yamato M, Takagi R, Namiki H, Okano T. Membrane-permeable calpain inhibitors promote rat oral mucosal epithelial cell proliferation by inhibiting IL-1a signaling. PLoS One 2015; 10: 0134240.

13. Atsuta I, Ayukawa Y, Kondo R, Oshiro W, Matsuura Y, Furuhashi A, Tsukiyama Y, Koyano K. Soft tissue sealing around dental implants based on histological interpretation. J Prosthedontic Res 2016; 60: 3-11.

14. Berglundh $\mathrm{T}$, Lindhe J. Dimension of the periimplant mucosa. Biological width revisited. J Clin Periodontol 1996; 23: 971-973.

15. Zhang LQ, Li DY. Biological characteristic comparison between long junctional epithelium cells and junctional epithelium cells. Shanghai Kou Qiang Yi Xue 2009; 18: 386-391.
16. Shimono $M$, Ishikawa $T$, Ishikawa $H$, Matsuzaki $H$, Hashimoto S, Muramatsu T, Shima K, Matsuzaka K, Inoue T. Regulatory mechanisms of periodontal regeneration. Microscopy Res Technique 2015; 60: 491-502.

17. Presland RB, Dale BA. Epithelial structural proteins of the skin and oral cavity: function in health and disease. Crit Rev Oral Biol Med 2000; 11: 383-408.

18. Wang Y, Cui H, Wu Z, Wu N, Wang Z, Chen X, Wei Y, Zhang P. Modulation of Osteogenesis in MC3T3-E1 Cells by Different Frequency Electrical Stimulation. PLoS One 2016; 11: 0154924.

19. Suzumura Y, Kameyama Y, Mizutani M, Kato M, Kondo $\mathrm{K}$, Mabuchi R. Long junctional epithelium produced by application of bacterial protease in rats. J Periodontal Res 1989; 24: 217-221.

\section{*Correspondence to}

Kenichi Matsuzaka

Department of Clinical Pathophysiology

Tokyo Dental College

Japan 